\title{
The mediating role of alexithymia in the association between attachment styles and borderline personality symptomatology
}

\section{Mohsen Khosravi}

\section{Department of Psychiatry and Clinical Psychology, Zahedan University of Medical Sciences, Zahedan, Iran}

\begin{abstract}
Attachment insecurity and alexithymia are assumed as the probable causes of emotional dysregulation in patients with Borderline Personality Disorder (BPD). The present study was designed and conducted to examine the mediating role of alexithymia in the relationship between attachment styles and Borderline Personality Symptomatology (BPS). In this crosssectional study, 153 patients with BPD were selected using stratified random sampling among outpatients referring to the psychiatric clinics in three major cities of Iran. Also, they were evaluated through the 20-item Toronto Alexithymia Scale (TAS20), Attachment Style Questionnaire (ASQ), and BPD Severity Index (BPDSI). On-way ANOVA and then Scheffé post-hoc
\end{abstract}

Correspondence: Mohsen Khosravi, Department of Psychiatry and Clinical Psychology, Zahedan University of Medical Sciences, Zahedan, Iran

Tel: +98-5433522636

E-mail: m.khosravi@zaums.ac.ir

Key words: Alexithymia, attachment, borderline personality disorder.

Acknowledgements: The author would like to thank the patients who contributed to performing the present study.

Conflict of interest: The author declares no conflict of interest.

Funding: None.

Availability of data and materials: The datasets generated and analyzed during the current study are not publicly available because no consent was obtained from the participants. However, the data are available by the corresponding author on a reasonable request.

Ethics approval and consent to participate: The study was approved by the ethics committee of the Medical Faculty of the ZAUMS Zahedan (IR.ZAUMS.REC.1397.428). Also, all procedures were according to the latest version of the Declaration of Helsinki. Prior to participation, written informed consent was obtained from all participants and their parents/legal guardians after a comprehensive explanation of the study procedures.

Received for publication: 10 February 2020.

Revision received: 20 June 2020

Accepted for publication: 1 July 2020.

This work is licensed under a Creative Commons AttributionNonCommercial 4.0 International License (CC BY-NC 4.0).

(C) Copyright: the Author(s), 2020

Licensee PAGEPress, Italy

Health Psychology Research 2020; 8:8894

doi:10.4081/hpr.2020.8894 analysis revealed that the scores of BPS and TAS-20, together with the scores of preoccupied, fearful, and dismissing styles, were higher in the alexithymia group, whereas the scores of secure style were greater in the non-alexithymia group. Furthermore, the results of hierarchical multiple regression analysis showed that alexithymia mediated the association between secure, preoccupied, and fearful styles and BPS based on the model proposed by Baron and Kenny. Hence, modifying the alexithymia need to be a goal of psychotherapy. In this regard, changing the effects of the problematic attachment styles via increasing emotional awareness may be effective in modifying alexithymia and BPS.

\section{Introduction}

The term alexithymia refers to a specific deficit in the emotional processing, which is identified as the inability to recognize and express the emotions, difficulty in differentiating the feelings from bodily sensations of emotional arousal, a paucity of fantasy life, and difficulty in regulating emotion and concrete cognitive style (Taylor, Bagby, \& Parker, 1999; Bermond, Bierman, Cladder, Moormann, \& Vorst, 2010; Stasiewicz et al., 2012). This personality construct prevents the understanding and representation of the affects and mental states through its affective and cognitive components, which avoids successful mentalization (De Panfilis, Ossola, Tonna, Catania, \& Marchesi, 2015). Despite extensive research, the etiology of alexithymia has remained unknown (Taylor \& Bagby, 2004). In this regard, the most promising perspective and research guidance is the attachment theory, showing how the parent-infant interaction patterns shape selfregulating features of the child's personality (Kobak, Cole, Ferenz $\square$ Gillies, Fleming, \& Gamble, 1993). Recent researches have shown that caregivers who do not express their emotions and use insufficient strategies for responding to children's negative emotions can have a profound effect on emotion regulation in adulthood (Carrère \& Bowie, 2012; Roque \& Veríssimo, 2011). Kobak et al. (1993) had formerly mentioned that the attachment relationship with the main caregiver in childhood has a fundamental role in the development of emotion regulation. Later on, this hypothesis was also confirmed biologically based on the statements of Schore (2000), indicating the role of attachment styles in the development of neural structures responsible for emotion regulation. Since alexithymia co-occurs with the difficulties in emotional self-regulation, it can be inferred that this trait is basically connected with the individual's attachment styles. Recent investigations have shown that alexithymia is more common in insecure attachment styles (Meins, Harris-Waller, \& Lloyd, 2008; Lyvers, Edwards, \& Thorberg, 2017; Oskis et al., 2013). Attachment insecurity, indeed, may ease the development of alexithymia personality features by causing failure in learning how to feel. Accordingly, the insecurely attached individuals have probably a low ability to identify and understand the emotional 
states that, in turn, leads to an increase in the risk of alexithymia (Besharat \& Khajavi, 2013).

Borderline Personality Disorder (BPD) is a severe mental illness characterized as a pervasive pattern of instability in affect regulation, impulse control, interpersonal relationship, and selfimage (Lieb, Zanarini, Schmahl, Linehan, \& Bohus, 2004). Patients with BPD are often assumed to be unable to identify the emotions and their causes. Hence, the inability to identify feelings seems to be a crucial factor in emotion dysregulation among patients with BPD (Wolff, Stiglmayr, Bretz, Lammers, \& Auckenthaler, 2007). This leads to the incorporation of alexithymia as a risk factor involved in the development of BPD (Bach, de Zwaan, Ackard, Nutzinger, \& Mitchell, 1994). Additionally, the experience of childhood maltreatment and inadequate parenting, which is accompanied by the insecure attachment in children, is also common among patients with BPD. Also, the preoccupied and fearful styles among insecure attachment dimensions have been highly related to BPD (Widom, Czaja, \& Paris, 2009).

Numerous studies have shown the association of attachment styles with alexithymia and the inability to identify feelings with borderline personality symptomatology (BPS). However, no research has been conducted on the relationship between attachment styles and BPS via alexithymia in adults. Thus, the present study is performed on patients with BPD based on the following hypotheses: i) The BPS is related to attachment; ii) The BPS is related to alexithymia; iii) Alexithymia mediates the association between attachment and BPS.

\section{Materials and Methods}

\section{Participants}

This cross-sectional study was conducted from April 2018 to October 2019. The sample size was calculated to be 161 individuals based on the Green's method $(\mathrm{N} \geq 50+8 \mathrm{p}=100+8 \times 5=140$; $\mathrm{p}$ : number of predictors), regarding $15 \%$ attrition of participants (Burmeister $\&$ Aitken, 2012). The participants were selected using stratified random sampling among outpatients referring to the Psychiatric Clinics in three major cities of Iran. The inclusion criteria were as follows: achieving a score $>10$ in Borderline Personality Inventory (BPI) and confirmed diagnosis through Structured Clinical Interview for DSM5 Personality Disorders (SCID-5-PD); aged 18 to 35; ability to read and write. Also, exclusion criteria consisted of: severe and acute physical illness; brain traumatic injury; comorbidity of bipolar disorder; comorbidity of schizophrenia and other psychotic disorders; epileptic disorders; intellectual disability; mixed personality disorder; and incorrectly completed questionnaire. Finally, 153 patients with BPD (including 63 men and 90 women) responded to the questionnaire correctly. The socio-demographic information of the participants is presented in Table 1.

\section{Procedure}

After obtaining the ethical approval from the Research Center of the Medicine Faculty and prior permission from the relevant Ethics Committee (with IR.ZAUMS.REC.1397.428 code of ethics), the subjects were given the consent form to sign. The study was performed according to the declaration of Helsinki as subjects were told that their participation was optional and they could leave the study for any reason. Then, participants were divided into three groups based on TAS-20 scores, namely non-alexithymia (cut-off score 51), possible alexithymia (cut-off score of 52-60), and alexithymia (cut-off score 61). Afterward, the Attachment Style Questionnaire (ASQ) and the Borderline Personality Disorder Severity Index (BPDSI) were administered to them. The names of the participants were not collected to keep the questionnaires anonymous.

\section{Measures}

\section{TAS-20}

In this study, a Persian version of the TAS-20 was used to measure the alexithymia level among participants. It included 20 questions and 3 subscales (difficulties in identifying feelings, difficulties in describing feelings, and externally oriented thinking), whose questions were scored on a 5-point Likert scale. The minimum and maximum scores of this scale are 20 and 100 , respectively. Also, a score 61 indicates the presence of alexithymia, and a score of 52-60 represents possible alexithymia. A score 51 implies the absence of alexithymia. In Iran, Besharat (2007) reported Cronbach's alpha for overall alexithymia and showed that the three subscales ranged between 0.72 and 0.85 .

\section{$A S Q$}

Attachment styles were assessed with the Persian version of ASQ. This questionnaire, first designed in 1991 by Bartholomew and Horowitz, included 24 questions and four secure, preoccupied, fearful, and dismissing subscales, being scored on a 5-point Likert scale (from 1 standing for "completely disagree" to 5 representing "completely agree"). Therefore, the minimum and maximum scores were 24 and 124, respectively. In Iran, Firoozabadi, Abedi, Aliyari, Zolfaghari, and Ghanizadeh, (2014) reported Cronbach's alpha for all items equal to 0.70 .

\section{BPDSI}

BPS was assessed with the Persian version of the BPDSI. This questionnaire included 70 questions to examine 9 criteria of BPD, including abandonment, relationships, identity disturbance, impulsivity, parasuicide, affective instability, emptiness, angercontrol, and dissociation. In Iran, Salavati (2007) reported the validity coefficient of this index to be 0.85 .

\section{BPI}

Patients' screening for BPD was performed using the Persian version of BPI. This inventory included 53 questions and 4 subscales of identity diffusion, primitive defense mechanisms, reality testing, and fear of closeness. In this inventory, if the cut-off score of the individual for the 20 questions is higher than 10, it is highly probable that he/she suffers from BPD. Mohammadzadeh

Table 1. Socio-demographic information of participants $(n=153)$.

\begin{tabular}{lll} 
Variables & N (\%) \\
Age & $18-23$ & $48(31.4)$ \\
& $24-29$ & $35(22.9)$ \\
\multirow{2}{*}{ Gender } & $30-35$ & $70(45.8)$ \\
& Male & $63(41.2)$ \\
Level of education & Female & $90(58.8)$ \\
& Elementary grade & $24(15.7)$ \\
& Middle grade & $33(21.6)$ \\
Marital status & High school & $32(20.9)$ \\
& Diploma and higher & $64(41.8)$ \\
& Married & $62(40.5)$ \\
& Single & $91(59.5)$ \\
\hline
\end{tabular}


(2011) examined the Farsi version of the inventory and reported its reliability and validity to be appropriate (Cronbach's alpha ranging between 0.70 and 0.85 ).

\section{SCID-5-PD}

BPD diagnosis was confirmed through SCID-5-PD. This instrument is a semi-structured diagnostic interview for clinicians and researchers to assess the 10 DSM-5 Personality Disorders across Clusters A, B, C, as well as other specified personality disorders. The reliability and validity of the SCID-5-PD were found suitable in different studies (First, Williams, Benjamin, \& Spitzer, 2016).

\section{Statistical Analysis}

The descriptive statistical methods, including mean and standard deviation, were used to examine the data. The one-way analysis of variance (ANOVA) was used to compare the mean of TAS-20, ASQ, and BPDSI scores according to the sociodemographic features. In one-way ANOVA, the Scheffé test was applied to the post-hoc analysis. Pearson's correlation coefficient was used to evaluate the correlations among the variables. Also, the model proposed by Baron and Kenny (1986) was adopted to investigate the mediating role of alexithymia in the relationship between attachment styles and BPS. According to this model, mediation exists if the four following conditions are met: i) the independent variable (attachment styles) affects the dependent variable (BPS); ii) the independent variable influences the mediator (alexithymia); iii) after considering the independent variable effect, the mediator affects the dependent variable; iv) after taking the mediator effect into account, the effect of the independent variable on the dependent variable decreases. Further, the hierarchical multiple regression analysis was performed to examine the predicting role of the study variables. All analysis steps were performed after the counter-effect of socio-demographic characteristics. The data analysis was carried out by SPSS Statistics V. 25, and the significance level was assumed less than 0.05 .

\section{Results}

\section{Preliminary analysis}

Table 2 compares the mean scores of secure style (F (2, $150)=43.37, \mathrm{p}<0.001)$, preoccupied style $(\mathrm{F}(2,150)=11.33$, $\mathrm{p}<0.001)$, fearful style $(\mathrm{F}(2,150)=18.84, \mathrm{p}<0.001)$, dismissing style $(\mathrm{F}(2,150)=4.89, \mathrm{p}<0.01)$, BPS $(\mathrm{F}(2,150)=92.86, \mathrm{p}<0.001)$, and
TAS-20 $(\mathrm{F}(2,150)=506.68 ; \mathrm{p}<0.001)$, showing a significant difference in the total alexithymia score. This difference is depicted in Figure 1, as simple error bars. The results of Figure 1 showed that the BPS and TAS-20 scores were greater in the group of alexithymia. Also, the scores of secure styles were bigger in the nonalexithymia group, and the scores of preoccupied, fearful, and dismissing styles were higher in the alexithymia group.

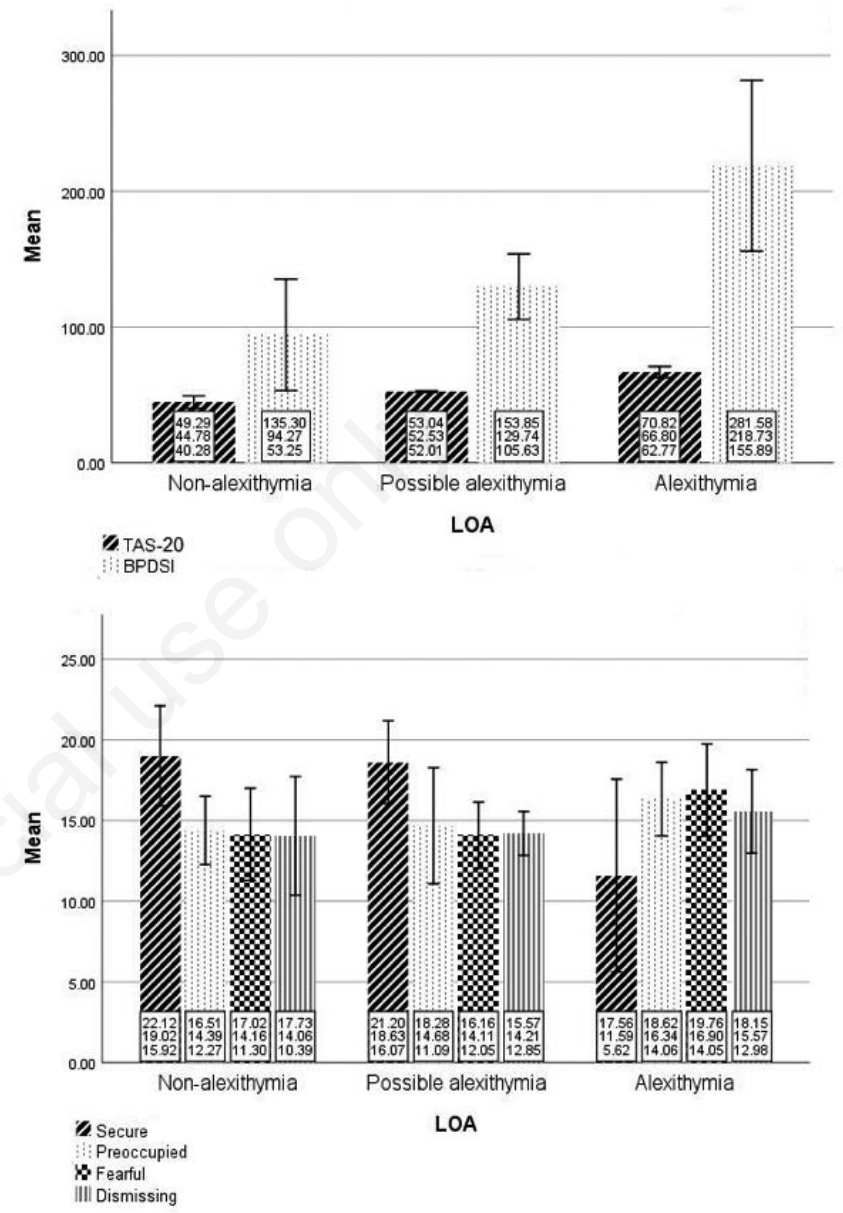

Figure 1. Simple error bar mean of TAS-20 scores, BPS, and attachment styles by LOA (Error bars: $95 \% \mathrm{CI}, \pm 1 \mathrm{SD})(\mathrm{N}=$ 153). BPS: Borderline Personality Symptomatology; LOA: Level of Alexithymia; TAS-20: 20-item Toronto Alexithymia Scale.

Table 2. Comparison of attachment styles, borderline personality disorder severity and the Toronto alexithymia scale (TAS-20) scores in terms of the total alexithymia score $(\mathrm{N}=153)$.

\begin{tabular}{|c|c|c|c|c|c|}
\hline Variables & $\begin{array}{c}N^{1} \\
(n=51) \\
M(S D)\end{array}$ & $\begin{array}{c}\mathrm{PA}^{2} \\
(\mathrm{n}=19) \\
\mathrm{M}(\mathrm{SD})\end{array}$ & $\begin{array}{c}A^{3} \\
(n=83) \\
M(S D)\end{array}$ & $F(2,150)$ & Scheffé post-hoc test \\
\hline Secure style & $19.01(3.10)$ & $18.63(2.56)$ & $11.59(5.97)$ & $43.37^{* * *}$ & $\mathrm{NA}>\mathrm{A}, \mathrm{PA}$ \\
\hline Preoccupied style & $14.39(2.11)$ & $14.68(3.59)$ & $16.33(2.28)$ & $11.33^{* * *}$ & $\mathrm{~A}>\mathrm{PA}, \mathrm{NA}$ \\
\hline Fearful style & $14.15(2.85)$ & $14.10(2.05)$ & $16.90(2.85)$ & $18.84^{* * *}$ & $\mathrm{~A}>\mathrm{PA}, \mathrm{NA}$ \\
\hline Dismissing style & $14.05(3.67)$ & $14.21(1.35)$ & $15.56(2.58)$ & $4.89^{* *}$ & $\mathrm{~A}>\mathrm{NA}$ \\
\hline BPS & $94.27(41.02)$ & $129.73(24.11)$ & $218.73(62.84)$ & $92.86^{* * *}$ & $\mathrm{~A}>\mathrm{PA}>\mathrm{NA}$ \\
\hline TAS-20 (total) & $44.78(4.50)$ & $52.52(0.51)$ & $66.79(4.02)$ & $506.68 * * *$ & $\mathrm{~A}>\mathrm{PA}>\mathrm{NA}$ \\
\hline
\end{tabular}

BPS: Borderline Personality Symptomatology; A: Alexithymia; NA: Non-alexithymia; PA: Possible alexithymia; TAS-20: 20-item Toronto Alexithymia Scale. ${ }^{1}$ The TAS-20 uses cut-off scoring: equal to or less than 51 ; ${ }^{2}$ The TAS-20 uses cut-off scoring: scores of 52 to $60 ;{ }^{3}$ The TAS-20 uses cut-off scoring: equal to or greater than $61 .{ }^{* *} \mathrm{p}<0.05 ;{ }^{* *} \mathrm{p}<0.01 ;{ }^{* * *} \mathrm{p}<0.001$ 


\section{Associations of study variables}

In addition, the results obtained from Table 3 showed that alexithymia had a significant correlation with secure style $(\mathrm{r}=-0.64$; $\mathrm{p}<0.01)$, preoccupied style $(\mathrm{r}=0.50 ; \mathrm{p}<0.01)$, and fearful style $(\mathrm{r}=0.54 ; \mathrm{p}<0.01)$. Also, there was a considerable correlation between the BPS and alexithymia $(r=0.82 ; \mathrm{p}<0.01)$, secure style $(\mathrm{r}=-0.88$; $\mathrm{p}<0.01)$, preoccupied style $(\mathrm{r}=0.62 ; \mathrm{p}<0.01)$, and fearful style $(\mathrm{r}=0.73 ; \mathrm{p}<0.01)$.

\section{Mediation analysis}

The results of regression analysis revealed that the secure style $(\beta=-0.66 ; p<0.001)$, preoccupied style $(\beta=0.14 ; p<0.001)$, and fearful style $(\beta=0.26 ; p<0.001)$ could predict BPS (Table 4$)$. Moreover, the secure style $(\beta=-0.45 ; \mathrm{p}<0.001)$, preoccupied style $(\beta=0.18 ; \mathrm{p}<0.05)$, and fearful style $(\beta=0.18 ; \mathrm{p}<0.05)$ could predict the total alexithymia score. Given the predictive role of total alexithymia score (TAS) $(\beta=0.33 ; \mathrm{p}<0.001)$, the relationship between the BPS and secure style $(\beta=-0.51 ; \mathrm{p}<0.001)$, preoccupied style $(\beta=0.08 ; \mathrm{p}<0.01)$, and fearful style $(\beta=0.20 ; \mathrm{p}<0.001)$ weakened, which indicated the mediating role of TAS based on the model proposed by Baron and Kenny.

\section{Discussion}

The results of the present work showed that the BPS and TAS20 scores were greater in the group of alexithymia, the scores of secure style were higher in the group of non-alexithymia, and the scores of preoccupied, fearful, and dismissing styles were higher in the alexithymia group. Besides, the results obtained from the correlation matrix revealed a significant correlation between the attachment styles, alexithymia, and BPS, i.e., the correlation between the secure style and other variables mentioned above was reported negative, but positive in other cases. These findings were consistent with the studies conducted by Besharat and Khajavi (2013), Lánge (2010), and Thorberg et al. (2011). Though different probabilities can be presented to explain these results, these relationships seemed to originate from the earlier stages of life (Oskis et al., 2013). Indeed, the mothers of securely attached children allow their children to express their positive and negative emotional states through open affect-related discussions (Leibowitz, Ramos-Marcuse, \& Arsenio, 2002). According to Cassidy (1994), the securely attached children seeking openly expression of their emotions are expected to receive strong emotional reactions from their caregivers. This early experience has an important role in completing the narrative abilities and emotional comprehension of secure children. Accordingly, they would have a correct understanding of their own and others' mental states and easily speak about their emotions (Besharat \& Khajavi, 2013). Thus, the sensitive and responsive mothers prepare a supportive context for their children to express feelings while validating their emotions by enhancing their comprehension, acceptance, and regulation of arduous emotions. In contrast, insecure children fail to understand and express their emotions due to their mothers' attention to external events. Also, they do not express negative emotions to avoid the anger of their caregivers (Besharat \& Khajavi, 2013; Lowe et al., 2012; Erickson \& Lowe, 2008).

Also, in the present study, the regression analysis demonstrated the role of secure, preoccupied, and fearful styles in predicting the alexithymia and BPS. The above findings were consistent with Bowlby's view, based on the type of secure attachment necessary for the exploration of internal states. This exploration leads to better identification of the emotions and allows promoting mature and

Table 3. Correlation matrix of study variables $(\mathrm{N}=153)$.

\begin{tabular}{|c|c|c|c|c|c|c|c|}
\hline Variables & M (SD) & 1 & 2 & 3 & 4 & 5 & 6 \\
\hline 1. Secure style & $14.94(6.05)$ & - & & & & & \\
\hline 2. Preoccupied style & $15.48(2.58)$ & $-0.47^{* *}$ & - & & & & \\
\hline 3. Fearful style & $15.64(3.07)$ & $-0.55^{* *}$ & $0.61^{* *}$ & - & & & \\
\hline 4. Dismissing style & $14.89(2.96)$ & $0.17^{*}$ & 0.03 & -0.11 & - & & \\
\hline 5. TAS & $166.19(78.49)$ & $-0.64^{* *}$ & $0.50 * *$ & $0.54^{* *}$ & 0.14 & - & \\
\hline 6. BPS & $57.68(10.95)$ & $-0.88 * *$ & $0.62^{* *}$ & $0.73^{* *}$ & -0.10 & $0.82^{* *}$ & - \\
\hline
\end{tabular}

BPS: Borderline Personality Symptomatology; TAS: Total Alexithymia Score. “* $\mathrm{p}<0.05 ;{ }^{* *} \mathrm{p}<0.01 ;{ }^{* * *} \mathrm{p}<0.001$

Table 4. Summary of regression analysis to assess the mediating role of alexithymia in the relationship between attachment styles and borderline personality symptomatology with controlling the effect of socio-demographic characteristics $(\mathrm{N}=153)$.

\begin{tabular}{|c|c|c|c|c|c|c|}
\hline Predicted variables & Variables in equation & $\mathbf{R}^{2}$ & $F(d f 1, d f 2)$ & $B(\beta)$ & SE & $\mathrm{t}$ \\
\hline BPS & $\begin{array}{l}\text { Secure style } \\
\text { Preoccupied style } \\
\text { Fearful style }\end{array}$ & $87.8 \%$ & $358.51(3,149)^{* * *}$ & $\begin{array}{c}-8.63(-0.66)^{* * *} \\
4.48(0.14)^{* * *} \\
6.85(0.26)^{* * *}\end{array}$ & $\begin{array}{l}0.45 \\
1.12 \\
0.99\end{array}$ & $\begin{array}{l}-18.94 \\
3.99 \\
6.86\end{array}$ \\
\hline TAS & $\begin{array}{l}\text { Secure style } \\
\text { Preoccupied style } \\
\text { Fearful style }\end{array}$ & $48.7 \%$ & $47.22(3,149)^{* * *}$ & $\begin{array}{c}-0.83(-0.45)^{* * *} \\
0.76(0.18)^{*} \\
0.64(0.18)^{*}\end{array}$ & $\begin{array}{l}0.13 \\
0.32 \\
0.28\end{array}$ & $\begin{array}{r}-6.36 \\
2.37 \\
2.26 \\
\end{array}$ \\
\hline BPS & $\begin{array}{l}\text { Secure style } \\
\text { Preoccupied style } \\
\text { Fearful style } \\
\text { TAS }\end{array}$ & $93.7 \%$ & $547.20(4,148)^{* * *}$ & $\begin{array}{c}-6.62(-0.51)^{* * *} \\
2.64(0.08)^{* *} \\
5.28(0.20)^{* * *} \\
2.41(0.33)^{* * *}\end{array}$ & $\begin{array}{l}0.37 \\
0.82 \\
0.73 \\
0.20\end{array}$ & $\begin{array}{c}-17.81 \\
3.19 \\
7.18 \\
11.67\end{array}$ \\
\hline
\end{tabular}

BPS: Borderline Personality Symptomatology; TAS: Total Alexithymia Score. “* $\mathrm{p}<0.05 ;{ }^{* *} \mathrm{p}<0.01 ;{ }^{* * *} \mathrm{p}<0.001$. 
efficient affect regulation. The secure children, who experience some type of optimum and cohesive response, while interacting with their primary caregiver, learn that the balanced expression of emotions has some positive results. Therefore, if the mother (primary caregiver) responds to the infant's needs more sensitively, the child's emotion regulation ability will be enhanced by developing a secure attachment. These abilities explain the negative role of secure attachment in predicting the alexithymia as the main index of emotional self-regulation (Taylor, Bagby, Kushner, Benoit, \& Atkinson, 2014). Further, the findings of the current work confirmed Linehan's model, where the invalidating environment yields the development of BPD. In this case, the individual with the unwarranted consideration of emotional displays damages the understanding and labeling of his/her emotions (Linehan, Heard, \& Armstrong, 1993). In this regard, Bartholomew \& Horowitz (1991) showed, based on Bowlby's concept of the internal working model, that negative model of self (including the preoccupied and fearful styles) are related to the anxiety concerning caregivers' availability, frequent verbal or physical contact with the caregivers, intense distress during separation, and anger and resistance at the caregivers' return. This anxiety makes people with a 'negative model of self' behave according to the caregivers' expectations, rather than those of their true selves (Hazan \& Shaver, 1987). Nonetheless, this model increases the vulnerability to the symptoms of BPD by compromising the proper identification of feelings, which entirely agrees with the theory of Fonagy, Target, \& Gergely (2000), indicating the role of 'alien self' induced by insensitive caregivers in the development of BPS.

Moreover, both the positive and negative model of others limit sharing the emotions through some concerns about being rejected and abandoned by others. This is the same hypothesis proposed earlier in Linehan's etiological model of BPD (Linehan et al., 1993).

As the first limitation, the cross-sectional design of the study prevented an understanding of relationships' exact nature, particularly with respect to causality. As the second restriction, the adults may report different attachment styles or security levels in response to certain life events based on the individual difference model. Thus, using family and peer attachment interviews (FPAI) can examine the present and past relationships of the patients while overcoming this limitation. On the other hand, disorganized attachment was introduced as one of the key factors in the development of borderline symptoms (Lyons $\square$ Ruth, 2008). Thus, it is necessary to consider this attachment dimension in future studies.

In sum, this study supported the mediating role of alexithymia in the association between preoccupied and fearful styles and BPS. Thus, modifying the alexithymia could be assumed as one of the treatment goals concerning the control of borderline personality symptoms. Therefore, psychotherapies (such as dialectical behavior therapy, schema therapy, interpersonal psychotherapy, attachmentbased psychotherapy, long-term psychodynamic psychotherapy, transference focused psychotherapy, and Mentalization-Bases Treatment) that alter the effects of problematic attachment styles via increasing emotional awareness, may be effective in modifying alexithymia and the BPS (Deborde et al., 2012, Khosravi \& Kasaeiyan, 2019). However, further research in this regard as clinical trials needs to be carried out.

\section{References}

Bach, M., de Zwaan, M., Ackard, D., Nutzinger, D.O., \& Mitchell,
J.E. (1994). Alexithymia: Relationship to personality disorders. Comprehensive Psychiatry, 35(3), 239-243.

Baron, R.M., \& Kenny, D.A. (1986). The moderator-mediator variable distinction in social psychological research: Conceptual, strategic, and statistical considerations. Journal of personality and social psychology, 51(6), 1173.

Bartholomew, K., \& Horowitz, L.M. (1991). Attachment styles among young adults: a test of a four-category model. Journal of personality and social psychology, 61(2), 226.

Bermond, B., Bierman, D.J., Cladder, M.A., Moormann, P.P., \& Vorst, H.C. (2010). The cognitive and affective alexithymia dimensions in the regulation of sympathetic responses. International Journal of Psychophysiology, 75(3), 227-233.

Besharat, M.A. (2007). Reliability and factorial validity of a Farsi version of the 20-item Toronto Alexithymia Scale with a sample of Iranian students. Psychological reports, 101(1), 209-220.

Besharat, M.A., \& Khajavi, Z. (2013). The relationship between attachment styles and alexithymia: Mediating role of defense mechanisms. Asian Journal of Psychiatry, 6(6), 571-576.

Burmeister, E., \& Aitken, L.M. (2012). Sample size: How many is enough?. Australian Critical Care, 25(4), 271-274.

Carrère, S., \& Bowie, B.H. (2012). Like parent, like child: Parent and child emotion dysregulation. Archives of psychiatric nursing, 26(3), e23-e30.

Cassidy, J. (1994). Emotion regulation: Influences of attachment relationships. Monographs of the society for research in child development, 59(2 $\square 3), 228-249$.

De Panfilis, C., Ossola, P., Tonna, M., Catania, L., \& Marchesi, C. (2015). Finding words for feelings: The relationship between personality disorders and alexithymia. Personality and Individual Differences, 74, 285-291.

Deborde, A.S., Miljkovitch, R., Roy, C., Dugré-Le Bigre, C., PhamScottez, A., Speranza, M., \& Corcos, M. (2012). Alexithymia as a mediator between attachment and the development of borderline personality disorder in adolescence. Journal of Personality Disorders, 26(5), 676-688.

Erickson, S.J., \& Lowe, J.R. (2008). The role of maternal responsiveness in predicting infant affect during the still face paradigm with infants born very low birth weight. Infant Mental Health Journal, 29(2), 114-132.

Firoozabadi, A., Abedi, Z., Aliyari, R., Zolfaghari, B., \& Ghanizadeh, A. (2014). Psychometric characteristics of the persian (farsi) version of attachment style questionnaire. Iranian journal of medical sciences, 39(6), 506.

First, M.B., Williams, J.B., Benjamin, L.S., \& Spitzer, R.L. (2016). User's Guide for the SCID-5-PD Structured Clinical Interview for DSM-5 Personality Disorders: Also Contains Instructions for the Structured Clinical Interview for DSM-5 Screening Personality Questionnaire. American Psychiatric Assoication Publishing.

Fonagy, P., Target, M., \& Gergely, G. (2000). Attachment and borderline personality disorder: A theory and some evidence. Psychiatric Clinics, 23(1), 103-122.

Hazan, C., \& Shaver, P. (1987). Romantic love conceptualized as an attachment process. Journal of personality and social psychology, 52(3), 511.

Khosravi, M., \& Kasaeiyan, R. (2019). Attachment Style and Its Relation to the Quality of Life and Readiness to Change Substance Use Behavior: A Causal-Comparative Study. Archives of Pharmacy Practice, 1, 35.

Kobak, R.R., Cole, H.E., Ferenz $\square$ Gillies, R., Fleming, W.S., \& Gamble, W. (1993). Attachment and emotion regulation during mother $\square$ teen problem solving: A control theory analysis. Child 
development, 64(1), 231-245.

Láng, A. (2010). Attachment and emotion regulation-clinical implications of a non-clinical sample study. Procedia-Social and Behavioral Sciences, 5, 674-678.

Leibowitz, J., Ramos-Marcuse, F., \& Arsenio, W.F. (2002). Parentchild emotion communication, attachment, and affective narratives. Attachment \& human, 4(1), 55-67.

Lieb, K., Zanarini, M. C., Schmahl, C., Linehan, M. M., \& Bohus, M. (2004). Borderline personality disorder. The Lancet, 364(9432), 453-461.

Linehan, M. M., Heard, H. L., \& Armstrong, H. E. (1993). Naturalistic follow-up of a behavioral treatment for chronically parasuicidal borderline patients. Archives of general psychiatry, 50(12), 971-974

Lowe, J. R., MacLean, P. C., Duncan, A. F., Aragón, C., Schrader, R. M., Caprihan, A., \& Phillips, J. P. (2012). Association of maternal interaction with emotional regulation in 4-and 9-month infants during the Still Face Paradigm. Infant Behavior and Development, 35(2), 295-302.

Lyons $\square$ Ruth, K. (2008). Contributions of the mother-infant relationship to dissociative, borderline, and conduct symptoms in young adulthood. Infant Mental Health Journal, 29(3), 203218.

Lyvers, M., Edwards, M., \& Thorberg, F. (2017). Alexithymia, attachment and fear of intimacy in young adults. IAFOR Journal of Psychology \& the Behavioral Sciences, 3, 1-11.

Meins, E., Harris-Waller, J., \& Lloyd, A. (2008). Understanding alexithymia: Associations with peer attachment style and mindmindedness. Personality and Individual Differences, 45(2), $146-152$

Mohammadzadeh, A. (2011). Validation of the borderline personality inventory in Iran. International Journal of Behavioral Sciences, 5(3), 269-277.

Oskis, A., Clow, A., Hucklebridge, F., Bifulco, A., Jacobs, C., \& Loveday, C. (2013). Understanding alexithymia in female adolescents: The role of attachment style. Personality and Individual Differences, 54(1), 97-102.
Roque, L., \& Veríssimo, M. (2011). Emotional context, maternal behavior and emotion regulation. Infant Behavior and Development, 34(4), 617-626.

Salavati, M. (2007). Most schemas and schematherapy efficacy in patients with borderline personality disorder. Clinical Psychology, phD Thesis. Tehran: Tehran Psychiatrist Institute, 189-200.

Schore, A.N. (2000). Attachment and the regulation of the right brain. Attachment \& human development, 2(1), 23-47.

Stasiewicz, P. R., Bradizza, C. M., Gudleski, G. D., Coffey, S. F., Schlauch, R. C., Bailey, S. T., Bole, C.V., \& Gulliver, S. B. (2012). The relationship of alexithymia to emotional dysregulation within an alcohol dependent treatment sample. Addictive behaviors, 37(4), 469-476.

Taylor, G.J., \& Bagby, R.M. (2004). New trends in alexithymia research. Psychotherapy and psychosomatics, 73(2), 68-77.

Taylor, G. J., Bagby, R. M., \& Parker, J. D. (1999). Disorders of affect regulation: Alexithymia in medical and psychiatric illness. Cambridge University Press.

Taylor, G. J., Bagby, R. M., Kushner, S. C., Benoit, D., \& Atkinson, L. (2014). Alexithymia and adult attachment representations: Associations with the five-factor model of personality and perceived relationship adjustment. Comprehensive Psychiatry, 55(5), 1258-1268.

Thorberg, F.A., Young, R.M., Sullivan, K.A., Lyvers, M., Connor, J.P., \& Feeney, G.F. (2011). Alexithymia, craving and attachment in a heavy drinking population. Addictive behaviors, 36(4), 427-430.

Widom, C. S., Czaja, S. J., \& Paris, J. (2009). A prospective investigation of borderline personality disorder in abused and neglected children followed up into adulthood. Journal of personality disorders, 23(5), 433-446.

Wolff, S., Stiglmayr, C., Bretz, H. J., Lammers, C. H., \& Auckenthaler, A. (2007). Emotion identification and tension in female patients with borderline personality disorder. British Journal of Clinical Psychology, 46(3), 347-360. 